\title{
Do Not Play with Fire
}

\author{
Antonio Villa*, Anna Kostihova, Simona Cattaneo, Anna Maria Croce, Marta Luperto \\ Emergency Department, Pathological Anatomy Laboratory Service; \\ Fatebenefratelli Hospital, Milan, Italy \\ Email: *antonio.villa@fbf.milano.it
}

Received June 4, 2013; revised July 6, 2013; accepted July 13, 2013

Copyright (C) 2013 Antonio Villa et al. This is an open access article distributed under the Creative Commons Attribution License, which permits unrestricted use, distribution, and reproduction in any medium, provided the original work is properly cited.

\begin{abstract}
We report a case of exogenous lipoid pneumonia caused by inhalation of liquid paraffin in a fire eater young man. The patient was admitted to the Emergency Department because of acute retrosternal pain, dry cough and dyspnea. Chest radiograph showed multiple bilateral basal alveolar opacities associated to left pleural effusion; CT chest scan showed multiple bilateral areas of consolidation with cavity areas. BAL cytologic examination revealed abundant lipid-laden macrophages. Clinical symptoms resolved after corticosteroid treatment. Lipoid pneumonia is a rare and often underdiagnosed entity. The presence of lipid-laden macrophages in sputum or BAL fluid helps to confirm the diagnosis.
\end{abstract}

Keywords: Lipoid Pneumonia; Fire Eater; BAL Fluid

\section{Introduction}

Exogenous lipoid pneumonia is a rare disease that has traditionally been considered a chronic condition secondary to continued aspiration or inhalation of fatty substances. Sometimes an acute form may appear after a single aspiration of lipid material, being a characteristic accident of street artist or "fire-eaters" that may generate acute respiratory failure [1-3].

We report a case of pneumonia caused by inhalation of liquid paraffin in a fire eater young man.

\section{Case Report}

A 29-year-old male fire eater was admitted to the Emergency Department because of acute retrosternal pain, dry cough and dyspnea. Some hours before admission an accidental aspiration of liquid paraffin (Diavolina ${ }^{\circledR}$ ) occurred during a flame-blowing show.

On admission, PA was $120 / 80 \mathrm{mmHg}$, cardiac rate was $60 \mathrm{bpm}, \mathrm{SatO}_{2}$ was $94 \%$ and temperature $37.3^{\circ} \mathrm{C}$. Auscultation of the lungs was normal. Laboratory data showed leucocytosis $\left(18.300 / \mathrm{mm}^{3}\right)$ and high C reactive protein $(292 \mathrm{mg} / \mathrm{l})$.

Analysis of blood gases showed a $\mathrm{pO}_{2}$ of $72.1 \mathrm{mmHg}$, a $\mathrm{pCO}_{2}$ of $30.6 \mathrm{mmHg}$, a $\mathrm{pH}$ value of 7.45 and a $\mathrm{pO}_{2} /$ $\mathrm{FiO}_{2}$ of $344.7 \mathrm{mmHg}$.

Chest radiograph showed multiple bilateral basal alveolar opacities associated to left pleural effusion (Figure 1).

${ }^{*}$ Corresponding author.
Legionella and Pneumococcus urinary antigens were negative.

The patient was admitted in our ward and began antibiotic treatment with ceftriaxone and clarithromycin.

The patient was becoming progressively worse, with more cough and dyspnea on rest.

Inflammatory tests were high, hemocoltures were negative; HIV test was negative; serum Mycoplasma and Chlamydia tests were negative.

A CT chest scan showed multiple bilateral areas of consolidation with cavity areas (Figure 2).

Bronchoscopy and BAL fluid were performed. Results of all bacterial and fungal cultures remained negative. BAL cytologic examination revealed abundant lipidladen macrophages (Oil-Red coloration) (Figure 3).

Clinical symptoms resolved after appropriate corticosteroid treatment and the patient was discharged. At one month follow-up examination, laboratory data and chest radiograph were normal.

\section{Discussion}

Various practices can lead to exogenous lipoid pneumonia, e.g., the blowing of sesame oil through the nose in children in Southern India, the forcible feeding of ghee (clarified butter) in Saudi Arabia, the use of mineral oil to relieve small-bowel obstructions in Brazil and the use of gas-oil by fire-eaters [4].

Fire eaters during their show blow a combustible liquid to create a flame. Sometimes a part of this combusti- 


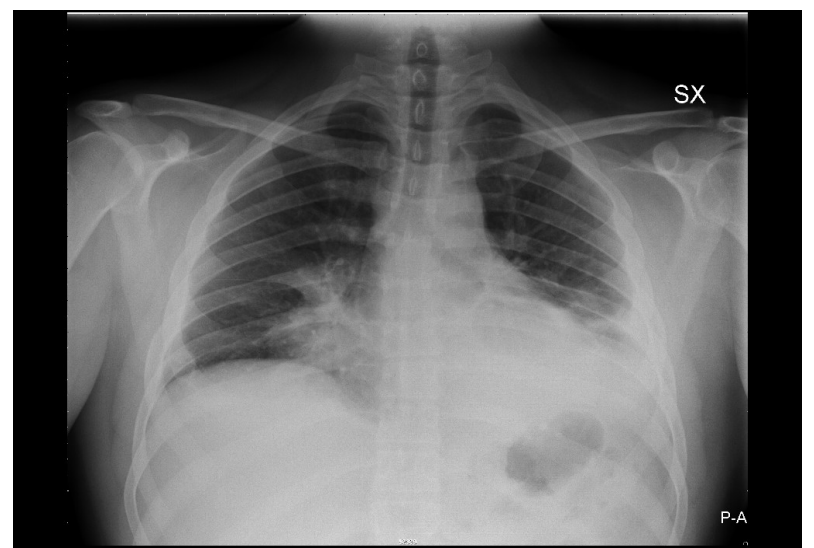

Figure 1. Chest X-ray shows bilateral alveolar opacities with left pleural effusion.

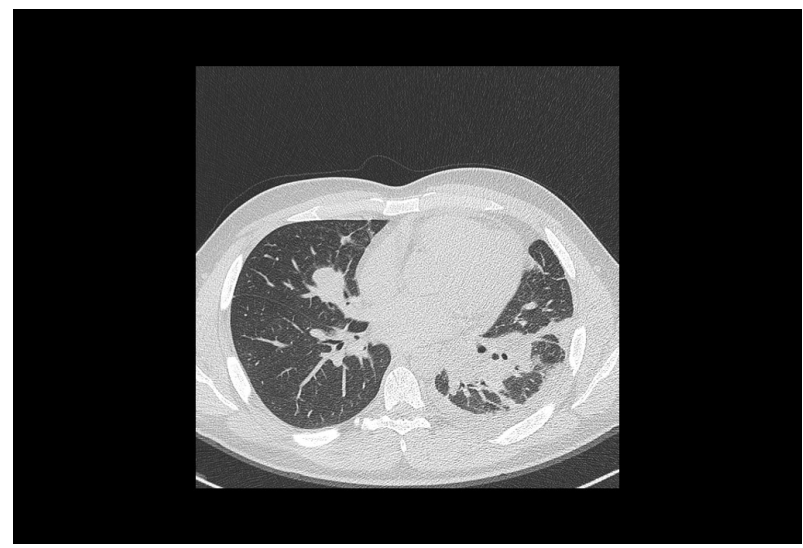

Figure 2. CT chest scan shows multiple parenchymal opacit ies with cavity areas.

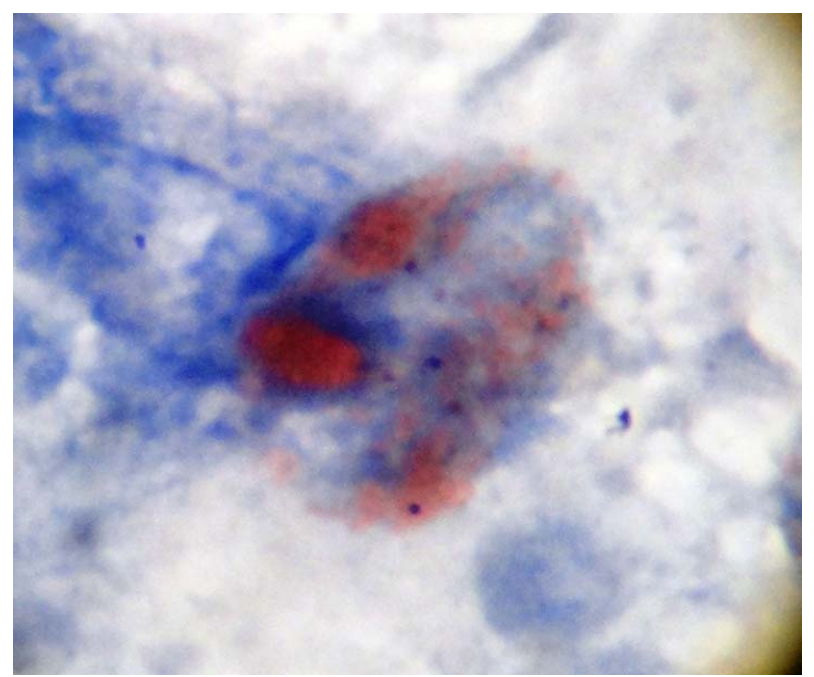

Figure 3. BAL fluid with lipid-laden macrophage (Oil Red coloration) $(1000 \times)$.

ble can be inspired.

Lipoid pneumonia is a rare, often underdiagnosed entity. Real incidence is not known; since 1970 about 80 cases in fire-eaters have been reported [1-3,5-14].

The diagnosis is frequently missed or delayed, and requires a high index of clinical suspicion [3].

Chest CT imaging typically shows bilateral alveolar consolidation and it is necessary to evaluate complications.

The presence of lipid-laden macrophages in sputum or BAL fluid helps to confirm the diagnosis [15].

The symptoms and pathologic changes often completely resolve with cessation of exposure; however, severe cases can progress to fibrosis and chronic respiratory failure [15].

\section{REFERENCES}

[1] T. Franquet, D. Gómez-Santos, A. Giménez, S. Torrubia and J. M. Monill, "Fire Eater's Pneumonia: Radiographic and CT Findings," Journal of Computer Assisted Tomography, Vol. 24, No. 3, 2000, pp. 448-450. doi:10.1097/00004728-200005000-00017

[2] C. Haas, F. X. Lebas, C. Le Jeunne, W. Lowenstein, H. Durand and F. C. Hugues, "Pneumopathies Caused by Inhalation of Hydrocarbons: Apropos of 3 Cases," Annales de Médecine Interne (Paris), Vol. 151, No. 6, 2000, pp. 438-447.

[3] J. C. Trullás Vila, S. Pizarro Serra, S. Nogué Xarau and S. Soler Simón, "Neumonia Lipoidea Exogena Aguda en 'Comedores de Fuego'. Descripcion de dos Casos," Revista Clínica Española, Vol. 207, No. 5, 2007, pp. 240242. doi:10.1157/13102316

[4] K. Harris, M. Chalhoub, R. Maroun, F. Abi-Fadel and F. Zhao, "Lipoid Pneumonia: A Challenging Diagnosis," Heart \& Lung, Vol. 40, No. 6, 2011, pp. 580-584. doi:10.1016/j.hrtlng.2010.12.003

[5] B. Beermann, T. Christensson, P. Moller and A. Stillstrom, "Lipoid Pneumonia: An Occupational Hazard of Fire Eaters,” British Medical Journal, Vol. 289, No. 6460, 1984, pp. 1728-1729. doi:10.1136/bmj.289.6460.1728

[6] P. E. Brander, E. Taskinen and B. Stenius-Aarniala, "FireEater's Lung,” European Respiratory Journal, Vol. 5, No. 1, 1992, pp. 112-114.

[7] A. Gondouin, P. Manzoni, E. Ranfaing, et al., "Exogenous Lipid Pneumonia: A Retrospective Multicenter Study of 44 Cases in France,” European Respiratory Journal, Vol. 9, No. 7, 1996, pp. 1463-1469. doi:10.1183/09031936.96.09071463

[8] L. Lores, L. J. Ribas, J. Ruiz, A. Cuxart, A. Frigola and J. Morera, "Acute Lipoid Pneumonia. Report of 2 Cases," Medicina Clínica (Barcelona), Vol. 106, No. 19, 1996, pp. 747-748.

[9] M. Personne, B. Lundholm and H. Persson, "Risk of Lung Damage Found in Fire-Eaters. Twelve Swedish Hospital Cases Reported,” Lakartidningen, Vol. 95, No. 45, 1998, pp. 4988-4989.

[10] B. Junge, W. Popp, S. Ruehm, A. W. Rettenmeier, U. Duhrsen and M. Runzi, "Fire Eater's Risk: Lipoid Pneumonia Following Aspiration of a Liquid Hydrocarbon 
Mixture,” Pneumologie, Vol. 56, No. 9, 2002, pp. 547549. doi:10.1055/s-2002-33852

[11] C. Lamour, C. Bouchaud, P. Doré, M. d'Arlhac and J. Bodin, "Pneumopathies par Inhalation d'Hydrocarbures Volatiles," Revue Des Maladies Respiratoires, Vol. 20, No. 6 (Pt 1), 2003, pp. 959-964.

[12] G. Deslee, F. Menivale, S. Dury, et al., "Pneumopathie des Cracheurs de Feu,” La Presse Médicale, Vol. 34, No. 21, 2005, pp. 1629-1633. doi:10.1016/S0755-4982(05)84238-1

[13] A. S. Costa, R. Noya, T. C. Calvo, R. Severo and A.
Afonso, "Exogenous Lipoid Pneumonia-Case Report," Revista Portuguesa de Pneumologia, Vol. 11, No. 6, 2005, pp. 567-572.

[14] L. Vimercati, A. Lorusso, S. Bruno, et al., "Polmonite Acuta da Aspirazione di Idrocarburi in un 'Mangiafuoco'," Giornale Italiano di Medicina del Lavoro ed Ergonomia, Vol. 28, No. 2, 2006, pp. 226-228.

[15] L. McCauley, C. Markin and D. Hosmer, "An Unexpected Consequence of Electronic Cigarette Use,” Chest, Vol. 141, No. 4, 2012, pp. 1110-1113.

doi:10.1378/chest.11-1334 